\title{
Health professionals talk about the challenges of suicide prevention in two correctional centres in South Africa
}

\author{
Pieter Nieuwoudt and Jason Bantjes
}

\begin{abstract}
Suicide is the leading cause of death among offenders in correctional facilities in many parts of the world. While epidemiological data have described the extent and scope of the problem, no research has documented the experiences and insights of health professionals who are tasked with providing care to suicidal offenders in South African correctional centres. It is within this context that we set out to document the experiences of a group of health professionals working in two correctional facilities in South Africa. We were interested in learning from them about their perceptions of the factors that contribute to suicidal behaviour among offenders and their suggestions for suicide prevention. In-depth semi-structured interviews were conducted with a group of health professionals $(N=10)$. Data were analysed using thematic analysis and an inductive approach was adopted for coding the data. The participants describe a number of structural and contextual factors which they believe make correctional centres in South Africa unsafe, thus increasing the risk of suicidal behaviour among offenders and hindering suicide prevention efforts within the two correctional centres where data were collected. These factors include high levels of psychopathology, trauma, substance abuse, violence, gangsterism, overcrowding, inadequate mental health care resources, and problems relating to stigma. These findings highlight human rights and mental health issues facing offenders and draw attention to conditions within correctional centres that need attention as part of any national suicide prevention strategy in South Africa.
\end{abstract}

\section{Keywords}

Correctional centres, offenders, prison, South Africa, suicide, suicide prevention

Suicide is the primary cause of death among offenders ${ }^{1}$ in many countries (Rivlin, Hawton, Marzano, \& Fazel, 2013), including South Africa (SA) (Judicial Inspectorate for Correctional Services [JICS], 2015]. Suicide prevention in correctional centres ${ }^{2}$ is a human rights issue as

Department of Psychology, Stellenbosch University, South Africa

Corresponding author:

Jason Bantjes, Department of Psychology, Stellenbosch University, Private Bag XI, Matieland 7602, South Africa.

Email: Jbantjes@sun.ac.za 
well as a public health concern (Lines, 2006). In spite of the prevalence of suicidal ideation and behaviour $^{3}$ (SIB) among offenders, comparatively little attention has been paid to suicide prevention in correctional centres, particularly in low- and middle-income countries (World Health Organization [WHO], 2012). Tartaro and Lester (2005) note that SIB in correctional centres has been largely neglected due to an attitude of apathy to the plight of offenders, and political and public disregard for this populations' psychological well-being and rights. Much of the research on offender SIB has focused primarily on the analysis of epidemiological data (Kovasznay, Miraglia, Beer, \& Way, 2004). There is a dearth of research describing health professionals' insights into offender suicide prevention. Understanding the experiences of health professionals who provide care to offenders could have important implications for suicide prevention by providing insight into reforms that are needed within correctional centres, particularly with respect to the organisation of mental health care, the allocation of resources, and professional training. It is within this context that we investigated the experience of providing care to suicidal offenders by health professionals working in two correctional centres in Cape Town, SA. Our intention was to explore insider perspectives and document the insights of this group of professionals in order to identify possible suicide prevention strategies. Our findings focus attention on contextual factors which impede suicide prevention within one medium- and one maximum-security correctional centre. We discuss the human rights and public health implications of these findings, within the context of the international literature on offender suicide prevention.

\section{SIB in correctional centres}

Suicide is the foremost cause of death among offenders in most Western countries, including the United Kingdom (Hawton, Linsell, Adeniji, Sariaslan, \& Fazel, 2014), Australia (Lyneham \& Chan, 2013), and the United States (Bark, 2014). Lekka, Argyriou, and Beratis (2006) suggest that suicide is 11-14 times more common among offenders than the general population. Other studies indicate that the prevalence of suicide among male offenders is $36: 100,000$, in contrast to a prevalence of 18:100,000 for males in the general public (Humber, Hayes, Senior, Fahy, \& Shaw, 2011). Rates of non-fatal suicidal behaviour (Daigle \& Côté, 2006) and suicidal ideation (Lekka et al., 2006) are also higher among offenders, compared to the general population.

A systematic review of studies $(N=34)$ concluded that risk factors for suicide in correctional centres were White race, being male, being married, occupying a single cell, detainee/remand status, serving a life sentence, recent suicidal ideation, history of attempted suicide, having a current psychiatric diagnosis, receiving psychotropic medication, and having a history of alcohol use problems (Fazel, Cartwright, Norman-Nott, \& Hawton, 2008). Rivlin et al. (2013) note that much of what we know about SIB in correctional facilities comes from studies in high-income western countries.

Approximately, 37\% of all natural deaths that occur in SA correctional centres (SACCs) are due to suicide, making suicide the primary cause of unnatural deaths (JICS, 2015). According to the Department of Correctional Services (DCS), there were 61 suicides in SACCs during 2015, yielding a prevalence rate of approximately 52:100,0004 (DCS, 2016). In 2010, Deon van Zyl, the then Inspecting Judge of Correctional Services, suggested that official DCS suicide figures underestimate the prevalence, since in most cases of death in SACCs there are no post-mortem examinations (JICS, 2010).

Most suicides in SACCs occur as a result of hanging or self-poisoning and occur between the evening lock-up and the time of the unlocking in the morning (DCS, 2016). The lock-up period during which suicides occur typically lasts for as long as $17 \mathrm{hr}$ and may be as long as $23 \mathrm{hr}$ in some SACCs as a result of staff shortages (Benatar, 2014). 


\section{Factors contributing to offender suicide}

SIB typically results from the interaction of a range of biological, social, personality, familial, environmental, and mental health factors (Rivlin et al., 2013). It is well established that SIB is associated with mental illness, principally depressive illnesses, substance use disorders (SUDs), personality disorders, post traumatic stress disorder, and psychotic illnesses (O'Connor, Platt, \& Gordon, 2011). SIB is also associated with sleep disturbances and a history of trauma (O'Connor et al., 2011). Some authors have affirmed that SIB is rare in the absence of mental illness (Cavanagh, Carson, Sharpe, \& Lawrie, 2003), although there is growing awareness of the role of situational and contextual factors in precipitating SIB (Douglas, 2015). There are significant gender differences in rates of SIB; rates of completed suicide are typically four times higher among men (O'Connor et al., 2011).

Correctional centres are typically populated by young men with a history of substance abuse, trauma, and mental health problems (Carli et al., 2011). As many as half of the offenders complain that they have difficulty with sleep (Carli et al., 2011). It is thus not entirely unexpected that rates of offender SIB would be high given the preponderance of risk factors in this population. It may be difficult and stressful, on incarceration, for offenders to adjust to the loss of freedom and control (O’Connor \& Sheehy, 2000). The stress of adapting to life within a correctional centre may precipitate SIB. Incarceration may also result in forced withdrawal from substances which can result in impulsive, irritable, and aggressive behaviour, including self-injury (Rivlin et al., 2013). Support for the idea that difficulty adjusting to incarceration may precipitate SIB is found in the fact that the highest occurrence of suicide is during the first days of incarceration (Humber et al., 2011; O'Connor \& Sheehy, 2000). There are also contextual factors within the correctional system that contribute to suicide including poor provision of mental health care, the lack of purposeful and stimulating activities such as work and education, social isolation, victimisation, and violence (Fazel, Grann, Kling, \& Hawton, 2011).

\section{Correctional centres in SA}

The DCS is responsible for the administration of SACCs and derives its legal mandate from the Correctional Services Act (Act 111 of 1998), Criminal Procedure Act (Act 51 of 1977), Child Justice Act (Act 75 of 2008), Promotion of Administrative Justice Act (Act 3 of 2000), and Prevention and Combating of Torture of Persons Act (Act 13 of 2013). The DCS is also governed by the 2005 White Paper on Corrections and the 2014 White Paper on Remand Detention Management in South Africa (South African Government, 2017). In accordance with this legislative and policy framework, the DCS is tasked with contributing to 'maintaining and promoting a just, peaceful and safe society by correcting offending behaviour in a safe, secure and humane environment' (South African Government, 2017, para. 2). Furthermore, the Constitution of the Republic of South Africa (RSA, Act 108 of 1996) requires the DCS to protect the rights of all offenders, including the right to human dignity, freedom and security of the person, satisfactory accommodation, and adequate medical care. Muntingh (2016) has noted that the DCS has fallen woefully short of its mandate to fulfil its statutory responsibilities, for a range of reasons including corruption, poor management, and lack of resources.

SACCs are not homogeneous entities; there is considerable variety in size and structure across different centres. In 2015/2016, there were 243 SACCs $^{5}$ (DCS, 2016), including two Public-Private Partnerships and nine women-only correctional centres. SACCs are classified as minimum-, medium-, and maximum-security facilities, depending on the profile of the inmates housed in these facilities and the level of security. 
Overcrowding is a major concern within SACCs. In 2015, a total of 161,984 offenders were housed within facilities that were equipped for 119,134; this represents $34 \%$ surplus (DCS, 2016). In 2014, Pollsmoor prison in Cape Town was operating at $238 \%$ occupancy (Benatar, 2014). As a result of overcrowding in many SACCs, the majority of offenders spend up to $23 \mathrm{hr}$ per day locked in a space smaller than a single mattress, offenders are sometimes forced to share beds, and there are insufficient bathroom facilities, inadequate supplies of toilet paper and soap, poor ventilation, and inadequately prepared and inedible food (Agboola, 2016; Benatar, 2014). Living under such conditions is inhumane and has an adverse impact on physical and mental health. Overcrowding in correctional facilities has been associated with elevated levels of psychological stress, psychiatric illness, interpersonal violence, physical assault, and sexual abuse, all of which contribute to increased risk of SIB (Cox, Paulus, \& McCain, 1984). Overcrowding in SACCs also leads to a lack of rehabilitation programmes, and extremely limited and often non-existent recreational or work opportunities (Benatar, 2014); this contributes to feelings of boredom, hopelessness, and being trapped, all of which are associated with increased risk of SIB (O'Connor et al., 2011). The factors contributing to overcrowding in SACCs are as follows: increases in lengths of sentences being handed down; changes in the offence profile of prison populations; changes in legislation which have extended the sentencing jurisdiction of magistrate, district and regional courts; and the introduction of mandatory minimum sentences (Giffard \& Muntingh, 2007).

Rates of psychopathology, including substance use, are high in SACCs. Naidoo and Mkize (2012) report that 55.4\% of offenders met Diagnostic and Statistical Manual of Mental Disorders, fourth edition (DSM-IV) diagnostic criteria for an Axis 1 disorder, most commonly psychotic, bipolar, depressive, and anxiety disorders. Rates of psychopathology are as high as $78.4 \%$ among offenders with sentences of more than 25 years (Prinsloo, 2013). Estimates of substance dependence among SA offenders range from $10 \%$ to $48 \%$ for males and from $30 \%$ to $60 \%$ for females (Booyens $\&$ Bezuidenhout, 2015). Offenders report that they have easy access to a range of substances within SACCs (Booyens \& Bezuidenhout, 2015), particularly cannabis (Naidoo \& Mkize, 2012).

Naidoo and Mkize (2012) found that the majority of mentally ill offenders in SACCs were neither diagnosed nor treated while incarcerated; for example, they found that eight out of nine offenders with a psychotic disorder were not receiving treatment. The DCS reports that in 2015, only $20.8 \%$ of inmates were engaged in psychological services (DCS, 2016). Providing adequate mental health care to offenders is hampered by problems, such as overcrowding and resource constraints (Muntingh, 2016). The JICS (2015) reported that in 32\% of SACCs, there were no doctors or nurses on the premises while 17 of SACCs had not received a visit from a doctor in the previous 3 months. Provision of health care to offenders is the responsibility of the DCS, not the Department of Health; as such, the DCS is tasked with deploying health professionals and establishing appropriate protocols and procedures (Benatar, 2014).

The high rates of violence and the nefarious influence of gangs within SACCs has been dramatically documented (Minnie, Prins, \& van Niekerk, 2002; Pinnock, 2016; Steinberg, 2004, 2005). Membership to a prison gang can be appealing; being part of these gangs can engender a sense of belonging, facilitate the formation of a 'new' identity to compensate for the loss of identity associated with incarceration, and provide access to substances and goods smuggled into the correctional centre (Minnie et al., 2002). Nearly, $80 \%$ of juvenile offenders cite protection from other inmates as the most common reason for prison gang membership (Peacock \& Theron, 2007). Gangs are, however, responsible for physical and sexual violence, thus contributing to making SACCs physically dangerous spaces. Approximately, $70 \%-80 \%$ of all awaiting-trial prisoners are sodomised before they are officially charged (Minnie et al., 2002).

It is within the context of these endemic systemic issues within SACCs that we set out to document health professionals' experiences of providing care to offenders at risk of suicide. Our aim 
was to explore the insider perspectives of health professionals working in two correctional centres and document their insights, as a first step towards identifying possible strategies to advance the goal of suicide prevention in SACCs.

The research question guiding this exploratory qualitative study was 'What can we learn about preventing offender suicide from the experiences of health care professionals working in two SACCs?'

\section{Method}

\section{Participants}

A group of 10 health professionals (six females and four males) from one maximum- and one medium-security correctional centre in Cape Town participated in this study. The age distribution of the sample was $27-51$ years, with a mean age of 39 years (standard deviation $[S D]=12$ ). The sample consisted of five psychologists, three medical sisters, one social worker, and one psychiatrist. Their work experience within DCS ranged from 6 months to 13 years, with an average of 6.2 years experience working in SACCs. Five of the participants self-identified as White, four identified as coloured, and one identified as Black.

\section{Instruments}

Data were collected via in-depth semi-structured interviews. Participants were asked about their experience of providing care to offenders, and their perception of the factors that contributed to SIB and impeded suicide prevention in SACCs. Examples of questions included in the interview were as follows: Tell me about your experience of working with suicidal inmates? What is your perception of the factors that hinder or promote suicide prevention in SACCs? What suggestions do you have for suicide prevention?

\section{Procedure}

Purposive criterion-based sampling was used to recruit participants with experience of working in SACCs. To meet inclusion criteria, participants had to be health care professionals currently employed by the DCS and had to have experience of working with suicidal offenders. There were no exclusion criteria. During 2015, all potential participants $(N=19)$ from two correctional centres were invited via email to participate in the study, of which 10 agreed to participate. Interviews were conducted at a time convenient to participants and in a private place. Interviews were audio recorded and transcribed and each lasted approximately $50 \mathrm{~min}$. In an effort to improve the trustworthiness of the findings, the interviewer repeatedly checked with participants to clarify what participants meant during the interviews and to confirm that what participants reported was being correctly interpreted.

\section{Ethical considerations}

Permission to conduct the study was obtained from the Health Sciences Research Ethics Committee at Stellenbosch University and the DCS. Participants gave written informed consent to participate in the study. Steps were taken to anonymise the data, protect the privacy of the participants, and store data securely. In the reporting of the findings, pseudonyms have been used to safeguard the identity of participants. 


\section{Data analysis}

Thematic content analysis was used to analyse the data employing an inductive approach and the systematic and methodical procedure outlined by Braun and Clarke (2006). Throughout data collection and analysis, detailed field notes and process notes were made in order to ensure dependability and promote reflexivity (Guba, 1981). To enhance credibility, we have provided verbatim quotes from interviews. We have also included data and quotes from all participant interviews to minimise the risk of bias in the reporting of findings. A rich description of both the study setting and the data collection process has been provided to improve the transferability of findings and to delineate the extent to which findings can be generalised. We have attempted to address the issue of transferability by discussing the findings within the context of relevant literature. Interviews were analysed independently by both authors, after which codes were compared in an effort to triangulate findings and improve the confirmability of the findings (Guba, 1981). Two superordinate themes emerged from the analysis: (1) systemic and contextual factors that impede suicide prevention and (2) the impact on participants of working with suicidal offenders in a resource scarce environment. In this article, we report on the first of these themes. We have focused on the first theme in order to provide an adequate exploration of the five subordinate themes identified within this superordinate theme, namely, high levels of psychopathology, violence and gangsterism, endemic substance use within SACCs, overcrowding and resource constraints, and stigma.

\section{Results}

Participants reported frequent contact with suicidal offenders. Des said, ' . . every time I have a session at the prisons, there is at least one person that exhibits such behaviour'. Participants identified the environment within correctional centres as being a major contributor to offender SIB. They described the environment as unsafe, dangerous, stressful, and hopeless. Des said, 'In terms of prison population, environmental stresses are often what precipitate suicidality'. Similarly, Lee explained, 'I think that almost everyone that lands up in prison thinks about it (suicide) at some stage; it's a very hopeless environment'.

Participants described a number of structural factors which they believe contribute to offender SIB, including high levels of psychopathology, violence, gangsterism, and substance abuse. Participants also identified overcrowding, inadequate mental health resources, and stigma about mental illness as impediments to suicide prevention. As a result of these structural problems, Lee concluded that '. . . prison is a much higher risk environment than virtually any other environment'.

\section{Psychopathology}

Participants noted the marked prevalence and severity of psychopathology among offenders, particularly mood and SUDs. They also said that many offenders had been exposed to trauma and had experienced attachment difficulties and traumatic abandonment. Lee articulated this by saying, 'There is a huge percentage of the prison population that have a mental illness'. Participants also noted that many offenders had a long-standing history of untreated psychiatric conditions and some offenders had a history of SIB prior to incarceration. Xolisa said, '. . there are a few that admitted to attempting in the past and landed up in hospital before they came to prison. But those are the people that have a long history of depression or psychotic disorders'. 


\section{Violence and gangsterism}

Participants said that interpersonal violence is commonplace in SACCs and is a major contributor to SIB. They noted that many offenders are incarcerated because of violent crimes and this contributes to creating an aggressive and physically unsafe environment which contributes to the stress of incarceration. Lee explained, 'Prison is a very unsafe environment. There is violence. It's gonna be traumatic'. Similarly, Des said, '. . . there might be other violent or dangerous people in close proximity'.

Participants noted that bullying and being victimised by other offenders act as precipitating factors for SIB. Xolisa said, 'It also pushes a lot of people to committing suicide, being victimised by their fellow inmates'. Similarly, Des said, ' . . . when patients tell me why they want to kill themselves, it is more what certain elements in the inmate population want to do to them. Or what they fear will be done to them'.

Participants explained that sometimes offenders are pressurised by gang members to participate in violence. Joey explained how this could precipitate SIB:

Sometimes it is the pressure in the cell, someone probably wants them to stab somebody else, that type of thing ... You are pressurised to stab somebody or whatever, but you don't want to do it, and that makes that people tell themselves afterwards, 'I am suppose to do it but I don't want to so instead I will rather take my life'.

Participants noted that many offenders had been members of gangs from a young age and that their gang affiliation continued once they were incarcerated. This gangsterism contributed to creating a hostile and unsafe environment.

Participants said they had seen some offenders become suicidal as a result of their gang membership. They explained how some offenders found themselves in unbearable situations being part of a gang and that suicide was perceived as the only way to exit the gang. Imraan explained, 'Sometimes they (suicidal offenders) are gang members and can't tolerate the pressure in the setup in which they find themselves. Then they will use it (suicide) as a way to escape from the gang'. Xolisa echoed this, saying, ' . . you can't resign or retire from it so the only way out is by killing yourself'.

\section{Substance use}

Participants noted that substance use was widespread among offenders and contributed to SIB. Sue said, 'I think that by the time they get to that stage (being incarcerated), they have been through substances a lot . . . I would say that $99.9 \%$ of patients that I deal with are on some sort of substance'.

Participants expressed a perception that substance use was related to gang activity. They also said there was a reciprocal relationship between substance use and other forms of mental illness; they noted how offenders had started using substances as a way of alleviating psychiatric symptoms, but they also said that substance use contributed to psychiatric problems. Lee said, 'A lot of them started self-medicating at the age of 12/13, and by becoming involved in drugs they became involved in gangs and started stealing and climbed as members of the gangs'.

Participants also noted that withdrawal from substances precipitated aggressive and self-injurious behaviour. Sue explained,

The problem with prisons are, you come and you don't necessarily have easy access to those substances you were using. They are there, but unless you are a member of the gang, or have money on your property, you don't have access to the quick relief. 
Sue went on to explain how she had seen this lead to SIB.

Participants described the access to illicit drugs within SACCs as a systems failure. Lee said, ' $I$ guess it (suicide) just becomes a downward spiral - exacerbated by, you know, access to illegal drugs in prison. So, it feels much like a kind of systemic failure'.

\section{Overcrowding}

Participants described how overcrowding created interpersonal conflict and stress, which contributed to SIB. Lee explained, 'One of the worst things is overcrowding. So, our prison is at more than $300 \%$ capacity so, in our prison the meaning of being in a single cell means that you are with three other people'. Des said, 'I see overcrowding as a stressor'. Sue described the impact of this saying,

... you know these guys are literally head to head on their beds and side by side, so there is very little for them, or room for them to do anything in private ... everybody knows exactly what you doing, when you doing it, how you doing it and when you go to the toilet.

Participants said that overcrowding placed a burden on resources and had an adverse impact on the ratio of correctional officials to offenders. Lee explained, 'The problem is that overcrowding means that the centres are understaffed for the capacity that they supposed to be at'. Imraan said that overcrowding created an 'inhuman' system. Participants explained how overcrowding put staff under pressure and compromised the management of SACCs. In this context, participants noted how difficult it was for prison officials to perform their duties and work within an overcrowded system. Lee said,

. . . but I must say, considering how poor the system is, I am often impressed with the members (prison officials) - the lengths that they do go to, because the system works against them as well. So, I am often impressed at the level of humanity that they can display in a very inhuman system.

Participants also said that overcrowding sometimes made it difficult for mental health workers to carry out their duties and contributed to the problem of inadequate mental health resources. Lee explained that it was not always possible to provide offenders with medication for depressive illnesses and that this resulted in more severe depressive symptoms which increased the risk of suicide:

It is for example very difficult to get access to the drugs. So, I think you do see a lot of untreated depression. So, that for me would be a common factor that why somebody who might be significantly and clinically depressed ... and it wouldn't be picked up or might get picked up but not responded to adequately ...

\section{Stigma}

Participants said that it was difficult to provide care when offenders failed to disclose their mental health issues and refused treatment. They said that mental illness was stigmatised and that many offenders saw mental illness as a sign of weakness. Lee said, 'It's difficult for them to accept adequate health care and mental health care, even once they have access'. Sue said, 'There is a bit of a taboo to them like showing themselves as being weak and vulnerable'. Participants said that offenders' lack of understanding about mental health issues and stigma resulted in low rates of treatment seeking. 
Table I. Strategies utilised within effective comprehensive multi-levelled Suicide Prevention Programmes (SPP) in correctional centres.

Screening and assessment of inmates on intake.

Improve staff training to identify at-risk offenders.

Post-intake observation for suicide risk.

Monitoring and psychological treatment of suicidal inmates.

Limited use of isolation.

Increased social support.

Adequate and safe housing facilities for at-risk individuals.

Improved referral systems and effective care of suicidal offenders.

Staff training on suicide prevention.

Legislation changes.

Targeted interventions for inmates with Borderline Personality Disorder.

Utilising trained peers (offenders) to provide social support to suicidal offenders.

Implementing standard procedures after suicide or suicide attempt (e.g., internal and external review

processes and staff debriefing and support).

Source: Barker, Kõlves, and De Leo (2014); Marzano et al. (2016).

\section{Discussion}

Our findings highlight systemic factors within two SACCs which need to be addressed in order to curb offender suicide. Participants believe that SIB is a function of high rates of psychopathology and substance use, inadequate access to mental health care, the availability of illicit substances, overcrowding, violence, and gangsterism in SACCs. There is evidence that the systemic factors identified by participants are widespread in SACCs, which suggest that the experiences and insights offered by participants in this study may be applicable to a number of other correctional facilities.

Participants strongly advocate addressing systemic issues within SACCs to promote the psychological well-being of offenders. This suggestion is entirely consistent with the small body of literature describing best practice in offender suicide prevention programmes (OSPPs). A systematic review of 12 studies evaluating OSPPs concluded that successful interventions are those which are comprehensive, multi-levelled, and employ a range of strategies to address individual, psychological, and contextual factors (see Table 1 for examples of effective multi-level strategies) (Barker, Kõlves, \& De Leo, 2014). A systematic review of studies of near-lethal suicide attempts in correctional centres concluded that best practice in OSPPs should entail screening and diversion of mentally disordered offenders (prior to and on incarceration); training staff to manage suicide risk; ensuring effective treatment and management of psychiatric disorders and psychosocial problems; instituting changes to the prison regime and environment (e.g., addressing issues such as bullying and social isolation); promoting protective factors (e.g., encouraging purposeful activity, meaningful social support, and positive interaction); making use of mentors and other forms of peer support; limiting access to lethal means of suicide; and providing training, support, and supervision for staff who encounter suicidal offenders.

Given the best practice literature on OSPPs and the insights of the participants in our study, it would seem vital to actively address the mental health of offenders in SACCs, particularly by providing targeted interventions for personality disorders and SUDs. The provision of health care in SACCs is hampered by lack of standard procedures for administration of health care or provision of medical personnel (South African Human Rights Commission [SAHRC], 1998) and the absence of a specific strategic plan for mental health care in SACCs (DCS, 2016). 
While the significant mental health treatment gap in SACCs is partially an issue of resource allocation, participants also believe that stigma acts as a barrier to offenders accessing and accepting mental health care. In this context, it is significant to note reports that $98 \%$ of offenders who requested mental health assistance received treatment (JICS, 2012). The extent to which stigma impacts help seeking needs further research, and it is important to consider other factors that may influence offenders' utilisation of available mental health services.

Participants believe that addressing substance use is integral to suicide prevention. This is, however, not a simple matter to address. In addition to the scarcity of mental health workers, overcrowding makes it difficult for members of the correctional services to control and monitor offenders. There is also the additional problem of no specific treatment approach or national strategy in place to deal with substance use among offenders in SACCs, despite the growing number of drug-related crimes and the marked prevalence of SUDs among offenders (Ovens, 2015). Ovens (2015) notes that previous treatment programmes for drug users in SACCs have been inadequate as they were developed for Western, high-resource contexts and were not culturally suitable.

Participants' perception of the need to address overcrowding and gangsterism in SACCs, as part of suicide prevention efforts, is not something typically found in the international literature on OSPPs. This is not surprising given that the literature on OSPPs comes almost exclusively from high-income Western settings where overcrowding and gangs present less of a problem within correctional centres. International literature on OSPPs does point to the role of bullying in precipitating offender suicide (Marzano et al., 2016), and clearly this is related to gangsterism. However, it would seem that gangs in SACCs are involved in more than bullying; they are responsible for violence, sexual assault, lawlessness, and supplying substances to offenders. The Commission of Inquiry into alleged incidents of corruption, maladministration, violence, or intimidation in the DCS (RSA, 2006) reported that sexual abuse and forced sexual activities occur regularly in all SACCs and are perpetrated mainly by prison gangs. Targeted interventions to address gangsterism in SACCs need to be integral to suicide prevention.

Participants advocate making SACCs more humane and less dangerous spaces, in order to curb suicide. SA subscribes to the retribution and safe custody objectives for imprisonment (Mubangizi, 2001). Furthermore, recent reforms within the DCS have tried to achieve a demilitarisation of the system; legislation has been established to transform the correctional system from a punitive organ of social control towards a more humane system focused on rehabilitation (Luyt, 2001; Mubangizi, 2001). Integral to these reforms has been the promulgation of the Constitutional Act 108 of 1996 (RSA, 1996) (which affirms offenders' right to life, privacy, equal protection, and dignity) and the Correctional Services Act 111 of 1998 (which specifically safeguards offenders' rights by requiring the state to provide for safe custody of prisoners under conditions of human dignity). However, as noted by the participants in our study, the extent to which this has been achieved is questionable. The National Prisons Project (SAHRC, 1998) concluded that the majority of SACCs fall short of their constitutional obligation to provide conditions consistent with human dignity.

Participants attribute offender suicide principally to external factors, such as overcrowding and violence, which are beyond the control of health professionals. International research confirms that these external factors are indeed important for suicide prevention. However, international research also strongly suggests that the most effective offender suicide prevention interventions are directly related to staff's everyday management of offenders and staff-prisoner relationships (Liebling, 2007; Liebling \& Tait, 2006). Health professionals working in SACCs are well positioned to effect changes in these aspects of correctional centre culture and to provide training to prison officials in this regard. To this end, there may be an urgent need to provide support to health care professionals in SACCs and to make them aware of international best practice in offender suicide prevention, so that they can play their part in addressing this important aspect of prisoner safety. 
Data were collected from two SACCs in one urban centre. As such, the data fail to describe variations in experiences that may occur in different correctional settings. It would be important for subsequent research to explore the experience of health care providers in a wider range of settings. This is particularly important, given Liebling's (2007) observation that 'Suicide prevention in prison requires attention to be paid to the needs and vulnerabilities of the prison population, which differ by prison' (p. 442). Collecting data from a broader cross-section of SACCs would make it possible to work towards the establishment of a set of clinical practice guidelines for the care of suicidal offenders and the establishment of a set of minimum norms and standards for suicide prevention in SACCs.

\section{Conclusion}

Our findings draw attention to structural problems within two SACCs which hinder suicide prevention and impede health professionals' ability to provide effective care to offenders. Addressing these issues is not only important from a public health and suicide prevention standpoint, but it is also important for human rights reasons and to ensure the integrity of the country's constitution. Psychology in SA has an important role to play in raising awareness of this issue, through research and advocacy work and by helping to develop and implement effective interventions to deal with the problems of endemic psychopathology, substance use, violence, and other systemic factors which make SACCs unsafe environments which can precipitate suicide. Crucially, health professionals working in SACCs have an important role to play in suicide prevention by utilising their knowledge, skills, and position to promote protective factors related to staff's everyday management and interaction with offenders.

\section{Funding}

The author(s) declared receipt of the following financial support for the research, authorship, and/or publication of this article: Jason Bantjes received financial support from the South African Medical Research Council (Career Development Award).

\section{Notes}

1. Offender is used to refer to any person, whether they have been convicted or not, who is detained in a residential correctional centre or in a remand detention facility.

2. In 2005, in accordance with The White Paper on Corrections in South Africa (SA), prisons in SA became known as 'correctional centres of rehabilitation' (hereafter referred to as 'correctional centres').

3. Suicidal ideation and behaviour (SIB) is a broad term that is used to encompass the full range of suicidal phenomena, including completed suicides, non-fatal SIB (i.e., suicide attempts), deliberate self-harm, and suicidal ideation (World Health Organization [WHO], 2014).

4. This is in contrast to a prevalence rate of 14:100,000 in the general population of SA (Bantjes \& Kagee, 2013).

5. During 2016, 11 centres were closed for upgrade, leaving only 232 active centres.

\section{ORCID iD}

Jason Bantjes (D) https://orcid.org/0000-0002-3626-9883

\section{References}

Agboola, C. (2016). Memories of the 'inside': Conditions in South African women's prisons. SA Crime Quarterly, 56, 19-26. doi:10.17159/2413-3108/2016/v0n56a43

Bantjes, J., \& Kagee, A. (2013). Epidemiology of suicide in South Africa: Setting an agenda for future research. South African Journal of Psychology, 43, 238-251. doi:10.1177/0081246313482627

Bark, N. (2014). Prisoner mental health in the USA. International Psychiatry, 11, 53-55. 
Barker, E., Kõlves, K., \& De Leo, D. (2014). Management of suicidal and self-harming behaviors in prisons: Systematic literature review of evidence-based activities. Archives of Suicide Research, 18, 227-240. doi:10.1080/13811118.2013.824830

Benatar, S. (2014). The state of our prisons and what this reveals about our society. South African Medical Journal, 104, 613-614. doi:10.7196/SAMJ.8608

Booyens, K., \& Bezuidenhout, C. (2015). Sex, drugs, and tattooing in correctional facilities and the relationship to STIs, HIV and AIDS. Acta Criminologica, 2, 144-159.

Braun, V., \& Clarke, V. (2006). Using thematic analysis in psychology. Qualitative Research in Psychology, $3,77-101$.

Carli, V., Roy, A., Bevilacqua, L., Maggi, S., Cesaro, C., \& Sarchiapone, M. (2011). Insomnia and SIB in prisoners. Psychiatry Research, 185, 141-144. doi:10.1016/j.psychres.2009.10.001

Cavanagh, J. T. O., Carson, A. J., Sharpe, M., \& Lawrie, S. M. (2003). Psychological autopsy studies of suicide: A systematic review. Psychological Medicine, 33, 395-405. doi:10.1017/S0033291702006943

Cox, V. C., Paulus, P. B., \& McCain, G. (1984). Prison crowding research: The relevance for prison housing standards and a general approach regarding crowding phenomena. American Psychologist, 39, 1148 1160. doi:10.1037/0003-066X.39.10.1148

Daigle, M. S., \& Côté, G. (2006). Nonfatal suicide-related behavior among inmates: Testing for gender and type differences. Suicide and Life-Threatening Behavior, 36, 670-681. doi:10.1521/suli.2006.36.6.670

Department of Correctional Services. (2016). Department of Correctional Services annual report 2015/2016: Financial year. Pretoria: Author. Retrieved from http://www.dcs.gov.za/?page_id=663

Douglas, J. D. (2015). Social meanings of suicide. Princeton, NJ: Princeton University Press.

Fazel, S., Cartwright, J., Norman-Nott, A., \& Hawton, K. (2008). Suicide in prisoners: A systematic review of risk factors. The Journal of Clinical Psychiatry, 69, 1721-1731.

Fazel, S., Grann, M., Kling, B., \& Hawton, K. (2011). Prison suicide in 12 countries: An ecological study of 861 suicides during 2003-2007. Social Psychiatry and Psychiatric Epidemiology, 46, 191-195. doi:10.1007/s00127-010-0184-4

Giffard, C., \& Muntingh, L. (2007). The numbering of days: Sentencing and prison population growth. $S A$ Crime Quarterly, 20, 21-30.

Guba, E. G. (1981). Criteria for assessing the trustworthiness of naturalistic inquiries. Educational Technology Research and Development, 29, 75-91.

Hawton, K., Linsell, L., Adeniji, T., Sariaslan, A., \& Fazel, S. (2014). Self-harm in prisons in England and Wales: An epidemiological study of prevalence, risk factors, clustering, and subsequent suicide. The Lancet, 383, 1147-1154. doi:10.1016/S0140-6736(13)62118-2

Humber, N., Hayes, A., Senior, J., Fahy, T., \& Shaw, J. (2011). Identifying, monitoring and managing prisoners at risk of self-harm/suicide in England and Wales. Journal of Forensic Psychiatry \& Psychology, 22, 22-51. doi:10.1080/14789949.2010.518245

Judicial Inspectorate for Correctional Services. (2010). Annual Report for the period 1 April 2009 to 31 March 2010. Retrieved from http://judicialinsp.dcs.gov.za/Annualreports/Annual\%20Report\%20 2009\%20-2010.pdf

Judicial Inspectorate for Correctional Services. (2012). 2011/2012 annual report. Retrieved from http://judicialinsp.dcs.gov.za/Annualreports/Annual\%20Report\%202011-2012.pdf

Judicial Inspectorate for Correctional Services. (2015). 2014/2015 annual report. Retrieved from http://judicialinsp.dcs.gov.za/Annualreports/JUDICIAL\%20INSPECTORATE\%20FOR\%20CORRECTIONAL\%20 SERVICES\%20ANNUAL\%20REPORT\%20FINAL2014-2015.pdf

Kovasznay, B., Miraglia, R., Beer, R., \& Way, B. (2004). Reducing suicides in New York State correctional facilities. The Psychiatric Quarterly, 75, 61-70.

Lekka, N. P., Argyriou, A. A., \& Beratis, S. (2006). Suicidal ideation in prisoners: Risk factors and relevance to suicidal behaviour: A prospective case-control study. European Archives of Psychiatry and Clinical Neuroscience, 256, 87-92.

Liebling, A. (2007). Prison suicide and its prevention. In W. Jewkes (Ed.), Handbook on prisons (pp. 423446). Devon, UK: Willan Publishing.

Liebling, A., \& Tait, S. (2006). Improving staff-prisoner relationships. In G. Dear (Ed.), Preventing suicide and other self-harm in prison (pp. 103-117). Basingstoke, UK: Palgrave Macmillan. 
Lines, R. (2006). From equivalence of standards to equivalence of objectives: The entitlement of prisoners to health care standards higher than those outside prisons. International Journal of Prisoner Health , 2, 269-280.

Luyt, W. (2001). The transformation of corrections in the new South Africa. Acta Criminologica, 14, 26-33. Lyneham, M., \& Chan, A. (2013). Deaths in custody in Australia to 30 June 2011. Canberra, Australia: Australian Institute of Criminology. Retrieved from http://aic.gov.au/media_library/publications $/ \mathrm{mr} /$ $\mathrm{mr} 20 / \mathrm{mr} 20 . \mathrm{pdf}$

Marzano, L., Hawton, K., Rivlin, A., Smith, E. N., Piper, M., \& Fazel, S. (2016). Prevention of suicidal behaviour in prisons: An overview of initiatives based on a systematic review of research on nearlethal suicide attempts. Crisis - The Journal of Crisis Intervention and Suicide Prevention, 37, 323-334. doi:10.1027/0227-5910/a000394

Minnie, M., Prins, A., \& van Niekerk, E. (2002). The role of prison gangs as precipitating agent in the spread of HIV/AIDS in South African prisons with special emphasis on socio-cultural factors. Acta Criminologica, 15, 51-62.

Mubangizi, J. C. (2001). Prisons and prisoners' rights: Some jurisprudential and historical perspectives. Acta Criminologica, 14, 120-129.

Muntingh, L. (2016). Assessing the state of South Africa's prisons. SA Crime Quarterly, 58, 35-44.

Naidoo, S., \& Mkize, D. (2012). Prevalence of mental disorders in a prison population in Durban, South Africa. African Journal of Psychiatry, 15, 30-35.

O’Connor R. C., Platt, S., \& Gordon, J. (Eds.). (2011). International handbook of suicide prevention: Research, policy and practice. Chichester, UK: John Wiley \& Sons, Ltd.

O’Connor, R. C., \& Sheehy, N. (2000). Understanding suicidal behaviour. Leicester, UK: BPS Books.

Ovens, M. (2015). Creating therapeutic communities for the treatment of substance-dependent offenders within South African correctional centres: A lesson from Sheridan Correctional Centre, Illinois, USA. Acta Criminologica, 28, 39-49.

Peacock, R., \& Theron, A. (2007). Identity development of the incarcerated adolescent with particular reference to prison gang membership. Acta Criminologica, 20(3), 61-74. Retrieved from https://repository. up.ac.za/bitstream/handle/2263/4094/Peacock_Identity(2007).pdf?sequence=1\&isAllowed=y

Pinnock, D. (2016). Gang town. Cape Town, South Africa: Tafelberg.

Prinsloo, J. (2013). Offenders with mental disorders in a South African prison population: Profiling the behavioural characteristics on mental illness. Journal of Psychology in Africa, 23, 133-138.

Republic of South Africa. (1996). Constitution of the Republic of South Africa No. 108 of 1996. Retrieved from http://www.gov.za/sites/www.gov.za/files/images/a108-96.pdf

Republic of South Africa. (2006). Commission of Inquiry into alleged incidents of corruption, maladministration, violence or intimidation in the Department of Correctional Services (Final report executive summary). Retrieved from http://www.info.gov.za/otherdocs/2006/jali/index.html

Rivlin, A., Hawton, K., Marzano, L., \& Fazel, S. (2013). Psychosocial characteristics and social networks of suicidal prisoners: Towards a model of SIB in detention. PLoS ONE, 8(7), e68944. doi:10.1371/journal. pone. 0068944

South African Government. (2017). Correctional services. Retrieved from http://www.gov.za/about-government/government-system/justice-system/correctional-services\#intro

South African Human Rights Commission. (1998). Report of the National Prisons Project of the South African Human Rights Commission. Braamfontein: Author.

Steinberg, J. (2004). Nongoloza's children: Western Cape prison gangs during and after apartheid. Braamfontein: Centre for the Study of Violence and Reconciliation.

Steinberg, J. (2005). The number: One man's search for identity in the Cape underworld and prison gangs. Cape Town, South Africa: Jonathan Ball Publishers.

Tartaro, C., \& Lester, D. (2005). An application of Durkheim's theory of suicide to prison suicide rates in the United States. Death Studies, 29, 413-422. doi:10.1080/07481180590932526

World Health Organization. (2012). Public health action for the prevention of suicide: A framework. Geneva, Switzerland: WHO Press. Retrieved from http://apps.who.int/iris/bitstream/10665/75166/1/9789241503570_ eng.pdf

World Health Organization. (2014). Preventing suicide: A global imperative. Geneva, Switzerland: WHO Press. Retrieved from http://apps.who.int/iris/bitstream/10665/131056/1/9789241564779_eng.pdf?ua=1\&ua=1 